\title{
Is an Intact Posterior Vertebral Body Cortex Protective for Percutaneous Ablation?
}

A fter the lung and liver, bone is the most common site for metastatic disease and the spine is the most common site of bony metastases. ${ }^{1}$ Roughly $70 \%$ of patients with cancer will develop metastatic disease. Of these, $40 \%$ develop spinal metastatic disease and $10 \%-20 \%$ of these will develop metastatic spinal cord compression. $^{2}$

Treatment of spinal metastases is usually palliative, with the goals of therapy including timely control of pain, local tumor control to prevent neurologic deficits, and mechanical stabilization to preserve function. ${ }^{2}$ Traditional treatment has been noninvasive, using analgesics, chemotherapy, and radiation therapy. Surgery is considered for radiation-resistant tumors, spinal instability, symptomatic neural compression, or intractable pain unresponsive to nonoperative measures. Recent studies have demonstrated image-guided invasive techniques of radiofrequency ablation (RFA), cryoablation, microwave ablation (MWA), and vertebral augmentation to be safe and effective in treating symptomatic metastatic osseous disease. ${ }^{3-8}$ The effects of different ablation modalities on the vertebral body and spinal cord are not completely understood.

The authors presented a study showing the ablation effects of bipolar RFA, cryoablation, and MWA on a normal sheep vertebral body and the adjacent spinal cord and nerve roots. ${ }^{9}$ The study addressed whether an intact posterior cortex of the vertebral body will be a protective barrier of the spinal cord and exiting nerve roots during the ablation. Second, the authors determined ablation zone dimensions for the 3 ablation modalities included in the study and correlated these with manufacturer's data. This is important because bone has different thermal and electrical conductive properties than a $37^{\circ} \mathrm{C}$ gel bath model used by the manufacturers to derive the ablation zones. Finally, the authors described the bone marrow changes seen after ablation on MR imaging and correlated these with pathologic specimens.

The study addressed the important point of whether a posterior intact cortex of the vertebral body will act as an insulator during ablation to prevent injury to the spinal cord. The authors showed that an intact posterior vertebral body cortex acts as an insulator when using a bipolar radiofrequency system; however, with cryoablation and MWA, this effect is not present and cord damage may occur. The results of previous animal experiments assessing the safety of RFA in proximity to the spinal cord have been inconclusive. ${ }^{10,11}$ However, these were monopolar RFA systems, whereas the current study used a bipolar system. There are no prior studies assessing the safety of cryoablation or MWA within the posterior vertebral body. This study showed that for cryoablation and MWA, the posterior vertebral body cortex does not act as an insulating barrier. For these 2 modalities, the ablation probes must be accurately placed in the vertebral body and the ablation zone must not extend past the posterior wall of the vertebral body to avoid injury to the spinal cord and nerve roots. Motor-evoked potential monitoring and peripheral motor nerve electrostimulation can be performed only with cryoablation and may prevent iatrogenic injury to the spinal cord and nerve roots. ${ }^{12,13}$

The RFA zones measured on gross pathology were smaller than those predicted from the manufacturer's $37^{\circ} \mathrm{C}$ gel bath model. However, the cryoablation and MWA zones were within 1 $\mathrm{mm}$ of those predicted from the manufacturer's preclinical data derived from the gel bath model. Awareness of this information is important for operators when performing ablation of a vertebral body.

Furthermore, the authors showed that ablation-induced marrow changes were similar on MR imaging, gross pathology, and histopathology across all 3 different ablation modalities. MR imaging showed the ablation area to be slightly hyperintense on T1weighted imaging, slightly hypointense on T2-weighted imaging, with a central area of nonenhancement and a peripheral rim of enhancement on the contrast-enhanced T1-weighted images. The ablation zone dimensions of all 3 modalities measured on gross pathology were larger than those measured on MR imaging. These findings are helpful for the diagnostic neuroradiologist and interventionalist interpreting the posttreatment images to determine whether there is residual tumor.

The main limitation of the experiment is that all ablations were performed in a normal vertebral body, which is not the same scenario as in the clinical setting. The ablation zone volumes obtained from the experiment may not correlate with vertebral bodies with tumor involvement, given the different impendence and 
thermal conductive properties of specific tumor types versus normal bone. Furthermore, the ablation zones derived from the experiment are specific to each manufacturer and cannot be generalized to other manufacturers of similar equipment.

The authors are to be commended for performing this in vitro experiment in a sheep model with the 3 most common ablation modalities. This report provides valuable information for operators performing vertebral body ablation with augmentation in patients with metastatic disease to the spine. With any palliative treatment, it is important to limit morbidity and maintain or improve quality of life. This information will help operators prevent injury to the adjacent spinal cord and nerve roots.

\section{REFERENCES}

1. Aaron $\mathrm{AD}$. The management of cancer metastatic to bone. JAMA 1994;272:1206-09 Medline

2. Klimo P Jr, Schmidt MH. Surgical management of spinal metastases. Oncologist 2004;9:188-96 CrossRef Medline

3. Anchala PR, Irving WD, Hillen TJ, et al. Treatment of metastatic spinal lesions with a navigational bipolar radiofrequency ablation device: a multicenter retrospective study. Pain Physician 2014;17: 317-27 Medline

4. Hillen TJ, Anchala P, Friedman MV, et al. Treatment of metastatic posterior vertebral body osseous tumors by using a targeted bipolar radiofrequency ablation device: technical note. Radiology 2014;273: 261-67 CrossRef Medline

5. Kastler A, Alnassan H, Aubry S, et al. Microwave thermal ablation of spinal metastatic bone tumors. J Vasc Interv Radiol 2014;25:1470-75 CrossRef Medline

6. Tomasian A, Wallace A, Northrup B, et al. Spine cryoablation: pain palliation and local tumor control for vertebral metastases. AJNR Am J Neuroradiol 2016;37:189-95 CrossRef Medline

7. Wallace AN, Greenwood TJ, Jennings JW. Radiofrequency ablation and vertebral augmentation for palliation of painful spinal metastases. J Neurooncol 2015;124:111-18 CrossRef Medline

8. Wallace AN, Tomasian A, Vaswani D, et al. Radiographic local control of spinal metastases with percutaneous radiofrequency ablation and vertebral augmentation. AJNR Am J Neuroradiol 2016;37: 759-65 CrossRef Medline

9. Wallace AN, Hillen TJ, Friedman MV, et al. Percutaneous spinal ablation in a sheep model: protective capacity of an intact cortex, correlation of ablation parameters with ablation zone size, and correlation of postablation MRI and pathologic findings. AJNR Am J Neuroadiol 2017;38:1653-59 CrossRef

10. Dupuy DE, Hong R, Oliver B, et al. Radiofrequency ablation of spinal tumors: temperature distribution in the spinal canal. AJR Am J Roentgenol 2000;175:1263-66 CrossRef Medline

11. Nour SG, Aschoff AJ, Mitchell IC, et al. MR imaging-guided radiofrequency thermal ablation of the lumbar vertebrae in porcine models. Radiology 2002;224:452-62 CrossRef Medline

12. Kurup AN, Morris JM, Boon AJ, et al. Motor evoked potential monitoring during cryoablation of musculoskeletal tumors. J Vasc Interv Radiol 2014;25:1657-64 CrossRef Medline

13. Franceschi F, Koutbi L, Gitenay E, et al. Electromyographic monitoring for prevention of phrenic nerve palsy in second-generation cryoballoon procedures. Circ Arrhythm Electrophysiol 2015;8: 303-07 CrossRef Medline

(D).J. Gemmete

University of Michigan Hospitals Ann Arbor, Michigan 